\title{
Assessment of the needs of hospice patients and their relatives by the Needs Evaluation Questionnaire
}

\begin{abstract}
Introduction: As the suffering affects both the patients with advanced illness and their family, the disease puts the closest ones under enormous stress. Palliative care, therefore, is offered also to relatives who demonstrate signs of adaptive disorders on confronting the situation. The aim of the study is to examine the needs in stationary hospice among the patients and their relatives.

Material and methods: The research group consisted of 338 persons - 181 palliative care patients and 157 relatives. The research took place in five stationary hospices in Poland. This study reconstructs the original version of Need Evaluation Questionnaire (NEQ) by Dr Marcello Tamburini questionnaire for the group of relatives in hospice.

Results: Almost half of the patients articulated the necessity to improve the control of the symptoms they were experiencing; slightly over $40 \%$ preferred to have a better information of the diagnosis and current progress of the illness. Almost half of the family members $(45.9 \%)$ declared the need to improve the control of the symptoms, followed by a "demand" for a better knowledge (40\%) about the diagnosis and the course of the illness. Least chosen was the information about insurance $(10.8 \%)$ and better quality of services (13.4\%).

Conclusions: Both groups of respondents demonstrated the similar intensity of needs associated with the perception of care. The most common need declared was one for a better control of the symptoms.
\end{abstract}

Palliat Med Pract 2018; 12, 4: 186-192

Key words: needs, hospice care, Need Evaluation Questionnaire

\section{Introduction}

Each year a growing demand for palliative care is observed. In this respect, it is vital to ensure professional treatment in accordance with guidelines laid out by the World Health Organization for patients with advanced diseases [1, 2]. In achieving this goal focusing on studies that explore the needs of patients — the direct receivers of care services - are important. One of the most important factors aggravating the suffering is social and psychological isolation and the notion of social rejection [3].

As the suffering affects both patients with advanced diseases and their families, the disease puts the closest ones under enormous stress. Palliative care, therefore, is offered also to the caregivers (such as families and closest associates) who demonstrate signs of adaptive disorders on confronting the situation. Through conversation, it is possible to ease the experience of sickness, death, and mourning. If the

\footnotetext{
Adres do korespondencji:

Karolina Włostowska

Cardinal Stefan Wyszyński University in Warsaw,

Faculty of Medicine. Collegium Medicum,

Wóycickiego 1/3 St., 01-938 Warsaw

e-mail: karolinapietruk@poczta.onet.pl 
sick person declares a high level of needs, the caregiver most likely experiences a heavy burden and high expectations. It is therefore vital to assess the needs of both from the very beginning [4].

The literature points to benefits resulting from studying the needs associated with care by applying the Need Evaluation Questionnaire (NEQ) by Dr Marcello Tamburini $[5,6]$. It is distinguished by a high compliance rate, short completion time and the absence of problems related to comprehension. It assures that the acquired information puts the patient in the centre as far as his health condition is concerned, allowing for full expression of opinions and discomforts. [7]. This helps to improve the quality of care and the quality of life of a patient. The aim of the study is to examine the needs in stationary hospice among the patients and their relatives.

\section{Material and methods}

The research group consisted of 338 persons -181 palliative care patients and 157 relatives. Most were people aged $60-80$ years. The number of those aged over 80 years accounted for $24.8 \%$ of the research group. Gender division was $54 \%$ women and $46 \%$ men. The age of persons visiting the patients was between 17 and 86 years. Half of the respondents were aged between 50 and 70 years $(33.1 \%)$, followed by a group of $30-50$-year-old (23.5\%). A selection of the research group of relatives was based on the frequency of visiting - minimum three times a week. For the patients, the criterion was a stay of at least seven days in the facility. Two out of three patients knew their condition (66\%), part was unaware $(14 \%)$ and the rest were unable to communicate the answer. The main cause for hospitalization was cancer (61.9\%). Some of the patients were admitted because of poor social conditions and lack of care from family (3.9\%), followed by stroke $(1.1 \%)$, accidents $(0.6 \%)$, postoperative complications $(0.6 \%$ - although most often they were related to cancer). Most common symptoms declared by patients were pain (36.5\%), weakness $(17.7 \%)$ and dyspnea (11.6\%). Over two-thirds of respondents (69\%) declared that they were aware of the place of stay. For families, the relevant indicator was slightly higher $(80 \%)$.

The research took place in five hospices - please list all hospices. Care in each facility was cost-free. In order to ensure the most honest answers possible and allow unrestrained expression of views, the questionnaire was carried out by persons not employed in the facilities.

Need Evaluation Questionnaire is a standardized questionnaire consisting of 23 dichotomous qu- estions. Its construction allows for answers as either "yes" - acknowledging the existence of a need- or "no". The most common everyday needs with regard to care in five main areas are listed: informative, concerning care and treatment, relational, psycho-emotional support and material. Questions from the original NEQ questionnaire are designed solely for patients. This study assumed the research should also include people who are not ill but are caregivers, namely the close ones. With this in mind, with the help of students and employees of the Warsaw Medical University, as well as with expert practitioners in palliative care, questions were redesigned for this particular group. The aim was to put the families in the centre as "care receivers" instead of "caregivers". This paper analyses the needs of the patients and their relatives by adapting the original NEQ developed by Dr Marcello Tamburini for the group of relatives in hospice.

\section{Statistical analysis}

To describe the examined group, the elements of descriptive statistics were used: mean average $(\bar{\chi})$, standard deviation (S), median (Me), a minimum value (Min), and a maximum value (Max.). Certain results were expressed as a percentage.

\section{Results}

\section{Assessment of the level of needs - patients}

Table 1 demonstrates the distribution of answers to 23 in-depth questions that form the NEQ questionnaire. Results were ordered from the most common declared need to the least valid. Almost half of the patients articulated the necessity to improve the control of the symptoms they were experiencing (question 9 from NEQ), and slightly over $40 \%$ preferred to have a better information of the diagnosis and current progress of the illness. Needs from psycho-emotional and material spheres were declared most rarely.

Table 2 shows the distribution of the number of needs declared in each area and a total sum. It must be noted that a different number of questions was associated with each sphere. Therefore a comparison of subsequent means is invalid.

\section{Assessment of the level of needs - the group of caregivers}

The assessment of needs associated with care that was declared by families was made using the NEQ questionnaire. The analysis was performed in the same way as the previous case. Table 3 describes the distribution of 23 in-depth questions that form the NEQ questionnaire. Results were ordered from most 
Table 1. Numeric and percentage range of the needs declared by patients

\begin{tabular}{|c|c|c|c|c|c|c|}
\hline \multirow[t]{2}{*}{ Need* } & \multicolumn{2}{|l|}{ No } & \multicolumn{2}{|l|}{ Yes } & \multicolumn{2}{|c|}{ No answer } \\
\hline & $\mathbf{N}$ & $\%$ & $\mathbf{N}$ & $\%$ & $\mathbf{N}$ & $\%$ \\
\hline (9) Controlling symptoms & 92 & $50.8 \%$ & 84 & $46.4 \%$ & 5 & $2.8 \%$ \\
\hline (1) Knowledge of diagnosis & 102 & $56.4 \%$ & 76 & $42.0 \%$ & 3 & $1.7 \%$ \\
\hline (2) Knowledge of the course of disease & 105 & $58.0 \%$ & 73 & $40.3 \%$ & 3 & $1.7 \%$ \\
\hline (18) Conversation with a priest & 107 & $59.1 \%$ & 70 & $38.7 \%$ & 4 & $2.2 \%$ \\
\hline (20) Support from close ones & 108 & $59.7 \%$ & 69 & $38.1 \%$ & 4 & $2.2 \%$ \\
\hline (21) The feeling of being needed & 103 & $56.9 \%$ & 69 & $38.1 \%$ & 9 & $5.0 \%$ \\
\hline (19) Conversation with other patients & 108 & $59.7 \%$ & 68 & $37.6 \%$ & 5 & $2.8 \%$ \\
\hline (6) Clear information & 112 & $61.9 \%$ & 64 & $35.4 \%$ & 5 & $2.8 \%$ \\
\hline (17) Conversation with a psychologist & 114 & $63.0 \%$ & 63 & $34.8 \%$ & 4 & $2.2 \%$ \\
\hline (22) Not feeling lonely & 108 & $59.7 \%$ & 63 & $34.8 \%$ & 10 & $5.5 \%$ \\
\hline (4) Knowledge of treatment & 114 & $63.0 \%$ & 62 & $34.3 \%$ & 5 & $2.8 \%$ \\
\hline (3) Knowledge of examinations & 117 & $64.6 \%$ & 58 & $32.0 \%$ & 6 & $3.3 \%$ \\
\hline (7) Honest information & 122 & $67.4 \%$ & 54 & $29.8 \%$ & 5 & $2.8 \%$ \\
\hline (10) Help with everyday activities & 127 & $70.2 \%$ & 50 & $27.6 \%$ & 4 & $2.2 \%$ \\
\hline (8) More conversations with doctors & 124 & $68.5 \%$ & 49 & $27.1 \%$ & 8 & $4.4 \%$ \\
\hline (16) Financial help & 133 & $73.5 \%$ & 45 & $24.9 \%$ & 3 & $1.7 \%$ \\
\hline (13) Assistance from doctors & 131 & $72.4 \%$ & 43 & $23.8 \%$ & 7 & $3.9 \%$ \\
\hline (12) More attention from nurses & 137 & $75.7 \%$ & 41 & $22.7 \%$ & 3 & $1.7 \%$ \\
\hline (5) Choice of treatment & 141 & $77.9 \%$ & 34 & $18.8 \%$ & 6 & $3.3 \%$ \\
\hline (11) Respect for patient's intimacy & 145 & $80.1 \%$ & 32 & $17.7 \%$ & 4 & $2.2 \%$ \\
\hline (14) Better quality of services & 148 & $81.8 \%$ & 28 & $15.5 \%$ & 5 & $2.8 \%$ \\
\hline (23) Fewer expressions of sympathy & 143 & $79.0 \%$ & 28 & $15.5 \%$ & 10 & $5.5 \%$ \\
\hline (15) Information about insurance & 155 & $85.6 \%$ & 22 & $12.2 \%$ & 4 & $2.2 \%$ \\
\hline
\end{tabular}

Table 2. Distribution of the needs declared in each segment

\begin{tabular}{llllll} 
Segment & $\bar{\chi}$ & Me & S & Min. & Max. \\
\hline Informative & 2.9 & 2 & 3.2 & 0 & 9 \\
\hline Associated with care & 0.7 & 0 & 1.0 & 0 & 3 \\
\hline Relational & 1.3 & 0 & 1.5 & 0 & 4 \\
\hline Psycho-emotional support & 1.1 & 1 & 1.0 & 0 & 3 \\
\hline Material & 0.5 & 0 & 0.8 & 0 & 3 \\
\hline Needs together & 7.0 & 6 & 5.6 & 0 & 23
\end{tabular}

often to the least declared need. They were grouped in the same way as for patients.

Almost half of the family members (45.9\%) declared the need to improve the control of the symptoms, followed by a "demand" for better knowledge (40\%) about diagnosis and course of illness. Least chosen was the information about insurance $(10.8 \%)$ and better quality of services (13.4\%). Numeric and percentage range of declared needs is shown in Table 4. It contains "statements" concerning needs. Full sentences can be found at end of this study (Appendix 1).

\section{Discussion}

A hospice is a place where death and suffering are common. The suffering of a dying person is composed of somatic symptoms that are exacerbated by a notion of helplessness, anxiety, fear, isolation and anger. Pro- 
Table 3. Numeric and percentage range of the needs declared by families

\begin{tabular}{|c|c|c|c|c|c|c|}
\hline \multirow[t]{2}{*}{ Needs* } & \multicolumn{2}{|l|}{ No } & \multicolumn{2}{|l|}{ Yes } & \multicolumn{2}{|c|}{ No answer } \\
\hline & $\mathbf{N}$ & $\%$ & $\mathbf{N}$ & $\%$ & $\mathbf{N}$ & $\%$ \\
\hline (9) Controlling symptoms & 79 & $50.3 \%$ & 72 & $45.9 \%$ & 6 & $3.8 \%$ \\
\hline (1) Knowledge of diagnosis & 89 & $56.7 \%$ & 65 & $41.4 \%$ & 3 & $1.9 \%$ \\
\hline (2) Knowledge of the course of disease & 89 & $56.7 \%$ & 65 & $41.4 \%$ & 3 & $1.9 \%$ \\
\hline (22) Not feeling lonely & 89 & $56.7 \%$ & 55 & $35.0 \%$ & 13 & $8.3 \%$ \\
\hline (3) Knowledge of examinations & 101 & $64.3 \%$ & 52 & $33.1 \%$ & 4 & $2.5 \%$ \\
\hline (7) Honest information & 100 & $63.7 \%$ & 51 & $32.5 \%$ & 6 & $3.8 \%$ \\
\hline (8) More conversations with doctors & 102 & $65.0 \%$ & 51 & $32.5 \%$ & 4 & $2.5 \%$ \\
\hline (12) More attention from nurses & 99 & $63.1 \%$ & 51 & $32.5 \%$ & 7 & $4.5 \%$ \\
\hline (4) Knowledge of treatment & 103 & $65.6 \%$ & 50 & $31.8 \%$ & 4 & $2.5 \%$ \\
\hline (20) Support from close ones & 100 & $63.7 \%$ & 48 & $30.6 \%$ & 9 & $5.7 \%$ \\
\hline (10) Help with everyday activities & 103 & $65.6 \%$ & 47 & $29.9 \%$ & 7 & $4.5 \%$ \\
\hline (11) Respect for patient's intimacy & 103 & $65.6 \%$ & 47 & $29.9 \%$ & 7 & $4.5 \%$ \\
\hline (18) Conversation with a priest & 103 & $65.6 \%$ & 47 & $29.9 \%$ & 7 & $4.5 \%$ \\
\hline (6) Clear information & 108 & $68.8 \%$ & 46 & $29.3 \%$ & 3 & $1.9 \%$ \\
\hline (19) Conversation with other patients & 105 & $66.9 \%$ & 44 & $28.0 \%$ & 8 & $5.1 \%$ \\
\hline (21) The feeling of being needed & 101 & $64.3 \%$ & 43 & $27.4 \%$ & 13 & $8.3 \%$ \\
\hline (23) Fewer expressions of sympathy & 102 & $65.0 \%$ & 41 & $26.1 \%$ & 14 & $8.9 \%$ \\
\hline (13) Assistance from doctors & 108 & $68.8 \%$ & 40 & $25.5 \%$ & 9 & $5.7 \%$ \\
\hline (16) Financial help & 112 & $71.3 \%$ & 36 & $22.9 \%$ & 9 & $5.7 \%$ \\
\hline (17) Conversation with a psychologist & 113 & $72.0 \%$ & 36 & $22.9 \%$ & 8 & $5.1 \%$ \\
\hline (5) Choice of treatment & 117 & $74.5 \%$ & 35 & $22.3 \%$ & 5 & $3.2 \%$ \\
\hline (14) Better quality of services & 129 & $82.2 \%$ & 21 & $13.4 \%$ & 7 & $4.5 \%$ \\
\hline (15) Information about insurance & 132 & $84.1 \%$ & 17 & $10.8 \%$ & 8 & $5.1 \%$ \\
\hline
\end{tabular}

Table 4. Total number of needs of families in each field

\begin{tabular}{llllll} 
Segment & $\bar{\chi}$ & Me & S & Min & Max \\
Informative & 3.0 & 2 & 3.0 & 0 & 9 \\
\hline Associated with care & 1.0 & 0 & 1.1 & 0 & 3 \\
\hline Relational & 1.3 & 1 & 1.3 & 0 & 4 \\
\hline $\begin{array}{l}\text { Psycho-emotional } \\
\text { support }\end{array}$ & 0.8 & 1 & 1.0 & 0 & 3 \\
\hline Material & 0.5 & 0 & 0.8 & 0 & 3 \\
\hline Needs together & 6.9 & 6 & 5.7 & 0 & 23 \\
\hline
\end{tabular}

gression of the illness aggravates these symptoms. As a result, patients' independence is being adversely affected as patients are more and more dependent on others. The literature states that the perception of time among people close to death is different. Time spent waiting for relief procedures lengthens [8]. The conducted research underlines the difficulties among medical staff and among patients to openly speak about needs [9]. Tools to examine the needs of patients play an important role in this field, especially when work has become a routine and a failure to notice clear changes in patient's behaviour [10]. Studies conducted in patients with advanced diseases have demonstrated that for them the most essential is a detailed knowledge of the disease and ways to deal with it [11]. The need most often chosen in the study utilizing the NEQ was the one associated with a more effective treatment of symptoms (46.4\%). Conducted research confirms that pain is the most common symptom declared by palliative care patients [12-15].

A professionally conducted conversation is the basis for recognizing a person's needs and in regaining a positive self-perception [16]. Cooperation based on a safe connection between both groups is crucial in the therapeutic process. Patient's individual preferences for the supply of information play a vital role in everyday clinical care [17]. Adjusting informational 


\section{Appendix 1}

Need Evaluation Questionnaire (for families)

Own elaboration (K. Włostowska) on the basis of the NEQ questionnaire by dr Tamburini

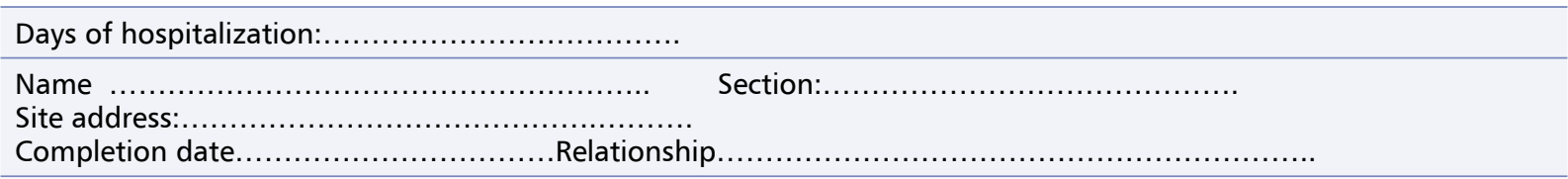

\section{Dear Sir/Madam,}

The following questionnaire contains a list of sentences that describe what you may experience during hospitalization. Please put a cross in the appropriate box. Tic "Yes" if you agree with the statement or "No" if it does not apply.

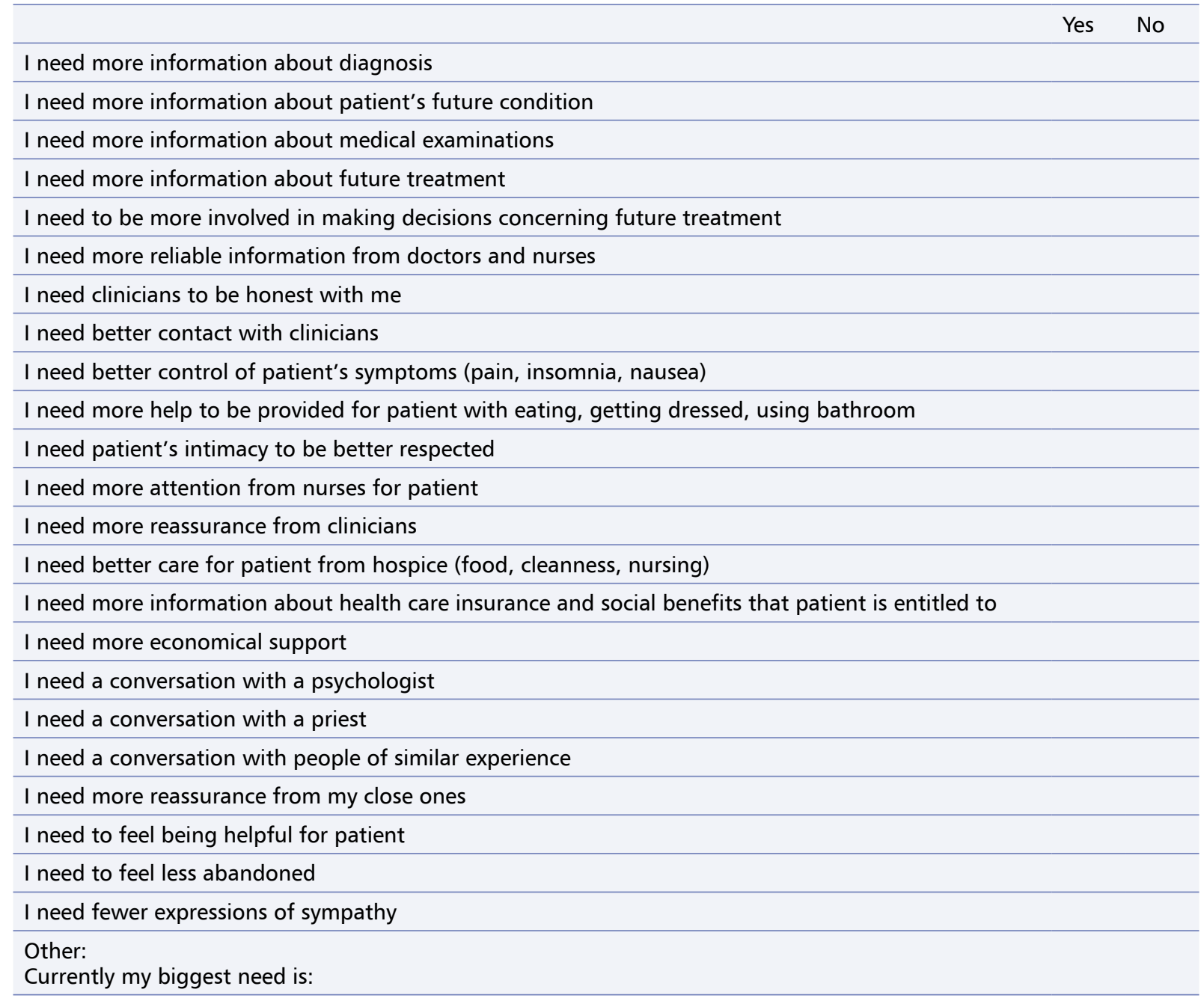

feedback for a particular person is intertwined with a continuous study of their preferences in a given sphere. Lack of a common language between doctors and patients is a serious challenge during care [18]. Based on the conducted research and analysis of the obtained results it can be concluded that the most important needs for both patients and families are the desire for complete information about the illness and ongoing treatment and monitoring of pain. The research demonstrates that no integrated system for palliative care patients exists which would address the needs most vital for them [19]. There is lack of feedback from patients about their view of palliative care. Only $10 \%$ of respondents stated that they had a conversation with doctors concerning their advanced disease situation. Our research showed that the 
needs in this sphere were not being satisfied. In the NEQ patients declared the need for more information, that is to expand knowledge about the diagnosis (42\%) and disease progression (40.3\%).

This research pointed to the fact that patients are interested not only in the knowing but also in making decisions by themselves (about the next steps of the treatment). It is a factor of great importance in the patient's life. Presently medicine underlines the right of cancer patients for complete and coherent information about disease, prognosis and emphasizes their involvement in the decision making process concerning treatment [20]. The way of approaching illness may differ from actively searching and demanding more information to a complete withdrawal [21]. There is no way of forecasting a person's demand in this area. Preferences can change instantly upon receiving the diagnosis. It is a fact that the disease affects biological, emotional, social and psychological spheres. It can influence the need for information [22]. According to Steptoe, it was proved that among those who avoid getting new information a level of satisfaction concerning sharing information was higher [23]. That is not to say that service users should be deprived of knowledge because that could be as harmful as forcing the information on those who do not want to be informed. Butow proved that passing information does not change a person's personality, but affects the ways that illness and care providers are perceived [24]. The necessity for routine verification of service users' needs in this field was emphasized.

Research using NEQ has revealed the needs from the material sphere to be of least importance $(\bar{\chi}-0,5)$. This may be due to the fact that the study was carried out in five facilities with free health care services (financed by the government). In a study carried out among palliative care patients and their families which included variables such as quality of life, depression, and fear, females, in general, showed more fearfulness and were more depressive than men. It was also demonstrated that psychological needs were not being satisfied. The authors do not specify exactly which needs and point to the fact that many are not yet assessed [25]. Many studies were conducted in different time periods, which brings many benefits. Changes in the intensity of needs can be tracked and adapt care accordingly. The literature demonstrates that the total number of caregivers from a family diminishes as the illness progresses [26]. Because of the fact that the research was carried out among patients with advanced diseases, it was impossible to reexamine them at regular intervals.

It is vital to identify patients' needs at every stage of their stay in the facility. In order to do so qu- estions from the NEQ in everyday conversations (if the patient's condition allows) rather than going on with a full inquiry should be used. The conducted research shows that the questionnaire is suited to hospice patients. It seems reasonable to employ this tool when working with students - future practitioners - because it focuses attention on the needs of the patient/family. That, in turn, should be a base point in planning care for patients with advanced diseases. For every person, the range of needs when considering care differs in character and intensiveness. The primary role is attached to discovering the needs of the patients. That is, to evaluate what kind of help is needed. Concern for satisfying one's needs will lead to the improvement in the overall quality of life. Properly assessed needs are a vital step in making a real change in the quality of care in hospices. Some wishes or needs may be impossible to satisfy. Such a situation could be accepted after facing a question if all that is possible was done for the patient in the given conditions. If several needs are equal, an evaluation of which are currently the most important for the patient should be determined.

\section{Conclusions}

The main objective of the research conducted was an assessment from the perspective of the effectiveness of palliative care among inpatient hospices of needs from the point of view of the patient and their close ones. Several conclusions may be drawn:

1. Both groups of respondents demonstrated the similar intensity of needs associated with a perception of care. The most common need declared was one for a better treatment of symptoms.

2. Both groups stated the information sphere to be of most importance.

3. The least indicated needs were those connected with material and psycho-emotional fields.

\section{References}

1. Davies E, Higginson IJ. Palliative care. The solid facts. WHO Regional Office for Europe, Copenhagen 2004.

2. Kapała P. de Walden-Gałuszko K. Ocena jakości opieki paliatywnej - zarys problemu. Psychoonkologia. 1999; 5: 37-43.

3. Levine PM, Silberfarb PM, Lipowski ZJ. Mental disorders in cancer patients: a study of 100 psychiatric referrals. Cancer. 1978; 42(3): 1385-1391, indexed in Pubmed: 698920.

4. Scaratti C, Leonardi M, Saladino A, et al. Needs of neuro-oncological patients and their caregivers during the hospitalization and after discharge: results from a longitudinal study. Support Care Cancer. 2017; 25(7): 2137-2145, doi: 10.1007/s00520-017-3619-6, indexed in Pubmed: 28204993.

5. Bonacchi A, Miccinesi G, Galli S, et al. Use of the Needs Evaluation Questionnaire with cancer outpatients. Support 
Care Cancer. 2016; 24(8): 3507-3515, doi: 10.1007/s00520016-3176-4, indexed in Pubmed: 27005464.

6. Tamburini M, Gangeri L, Brunelli C, et al. Cancer patients' needs during hospitalisation: a quantitative and qualitative study. BMC Cancer. 2003; 3: 12, indexed in Pubmed: 12710890.

7. Tamburini M, Gangeri L, Brunelli C, et al. Assessment of hospitalised cancer patients' needs by the Needs Evaluation Questionnaire. Annals of Oncology. 2000; 11(1): 31-37, doi: 10.1023/a:1008396930832.

8. Łuczak J, Kotlińska-Lemieszek A, Bączyk E. Cierpienia chorych u kresu życia. Opieka paliatywna/hospicyjna. Rozwój opieki paliatywnej/hospicyjnej w Polsce. Nowa Medycyna. 1999; 8: 9-13.

9. Fitzsimons D, Mullan D, Wilson JS, et al. The challenge of patients' unmet palliative care needs in the final stages of chronic illness. Palliat Med. 2007; 21(4): 313-322, doi: 10.1177/0269216307077711, indexed in Pubmed: 17656408.

10. Richardson A, Medina J, Brown V, et al. Patients' needs assessment in cancer care: a review of assessment tools. Support Care Cancer. 2007; 15(10): 1125-1144, doi: 10.1007/s00520-006-0205-8, indexed in Pubmed: 17235503.

11. Jenkins V, Fallowfield L, Saul J. Information needs of patients with cancer: results from a large study in UK cancer centres. Br J Cancer. 2001; 84(1): 48-51, doi: 10.1054/bjoc.2000.1573, indexed in Pubmed: 11139312.

12. Wilkes E, Crowther AG, Greaves CW. A different kind of day hospital--for patients with preterminal cancer and chronic disease. Br Med J. 1978; 2(6144): 1053-1056, indexed in Pubmed: 709216.

13. Sharma K, Oliver D, Blatchford G, et al. Medical care in hospice day care. J Palliat Care. 1993; 9(3): 42-43, indexed in Pubmed: 8271107.

14. Edwards A, Livingstone H, Daley A. Does hospice day care needs doctors? Palliative care today. 1997; 6: 36-37.

15. Goodwin DM, Higginson IJ, Myers K, et al. What is palliative day care? A patient perspective of five UK services. Support Care Cancer. 2002; 10(7): 556-562, doi: 10.1007/s00520002-0380-1, indexed in Pubmed: 12324811.

16. Elbert-Avila K, Tulsky J. Problems in Communication. Palliative Medicine. 2009: 625-630, doi: 10.1016/b978-0323-05674-8.50116-x.
17. Smith AK, Sudore RL, Pérez-Stable EJ. Palliative care for Latino patients and their families: whenever we prayed, she wept. JAMA. 2009; 301(10): 1047-57, E1, doi: 10.1001/jama.2009.308, indexed in Pubmed: 19278947.

18. Park ER, Betancourt JR, Miller E, et al. Internal medicine residents' perceptions of cross-cultural training. Barriers, needs, and educational recommendations. J Gen Intern Med. 2006; 21(5): 476-480, doi: 10.1111/j.1525-1497.2006.00430.x, indexed in Pubmed: 16704391.

19. Davison SN. End-of-life care preferences and needs: perceptions of patients with chronic kidney disease. Clin J Am Soc Nephrol. 2010; 5(2): 195-204, doi: 10.2215/CJN.05960809, indexed in Pubmed: 20089488.

20. Lantos J. Informed consent. The whole truth for patients? Cancer. 1993; 72(9 Suppl): 2811-2815, indexed in Pubmed: 8402509 .

21. Miller SM. Monitoring and blunting: validation of a questionnaire to assess styles of information seeking under threat. J Pers Soc Psychol. 1987; 52(2): 345-353, indexed in Pubmed: 3559895.

22. Degner L, Sloan J. Decision making during serious illness: What role do patients really want to play? Journal of Clinical Epidemiology. 1992; 45(9): 941-950, doi: 10.1016/0895-4356(92)90110-9.

23. Steptoe A, Sutcliffe I, Allen B, et al. Satisfaction with communication, medical knowledge, and coping style in patients with metastatic cancer. Soc Sci Med. 1991; 32(6): 627-632, indexed in Pubmed: 2035038.

24. Butow PN, Maclean M, Dunn SM, et al. The dynamics of change: cancer patients' preferences for information, involvement and support. Ann Oncol. 1997; 8(9): 857-863, indexed in Pubmed: 9358935.

25. Friðriksdóttir N, Saevarsdóttir T, Halfdánardóttir Sí, et al. Family members of cancer patients: Needs, quality of life and symptoms of anxiety and depression. Acta Oncol. 2011; 50(2): 252-258, doi: 10.3109/0284186X.2010.529821, indexed in Pubmed: 21231786.

26. Tsai PC, Yip PK, Tai JJ, et al. Needs of family caregivers of stroke patients: a longitudinal study of caregivers' perspectives. Patient Prefer Adherence. 2015; 9: 449457, doi: 10.2147/PPA.S77713, indexed in Pubmed: 25834409 